\title{
APRENDER DESDE LA EXPERIENCIA HISTÓRICA. REPRESENTACIONES DEL PROFESORADO SOBRE EL USO DE LA HISTORIA ORAL COMO ESTRATEGIA DIDÁCTICA ${ }^{1}$
}

\author{
To Learn from the Historical Experience: Teachers' Representations \\ about the Use of Oral History as a Didactic Strategy
}

\begin{abstract}
Belén Meneses Varas
profesora.belen.meneses@gmail.com Universidad Autónoma de Barcelona. España

Neus González-Monfort neus.gonzalez@uab.cat Universidad Autónoma de Barcelona. España

Antoni Santisteban Fernández antoni.santisteban@uab.cat Universidad Autónoma de Barcelona. España

Fecha de recepción: 01/03/2019 Fecha de aceptación: 14/06/2019
\end{abstract}

Resumen: El artículo aborda la experiencia histórica $\left(\mathrm{EH}^{2}\right)$ como un aspecto fundamental en la construcción del conocimiento histórico escolar. El objetivo del estudio es definir el significado de EH desde la didáctica de las ciencias sociales, reconocer su relación con la formación del pensamiento histórico y las formas de desarrollarla en los procesos de enseñanza y aprendizaje. Para ello se indaga en las representaciones del profesorado sobre el concepto de EH a partir de las reflexiones sobre

${ }^{1}$ Se presentan parte de los resultados de una investigación sobre el rol de la experiencia histórica en la formación del pensamiento histórico, en concreto a partir del uso de la historia oral en la enseñanza de la historia. La investigación se realiza desde el departamento de Didáctica de las Ciencias Sociales de la Universidad Autónoma de Barcelona. Es financiado por CONICYT PFCHA/DOCTORADO BECAS CHILE/2016 - 72170112.

2 El concepto de experiencia histórica será presentado mediante la abreviatura EH. 
sus prácticas de aula al utilizar la historia oral. Es una investigación cualitativa de tipo interpretativa, basada en un estudio de casos, que utiliza métodos mixtos para el análisis de los datos obtenidos de 33 cuestionarios y 8 entrevistas en profundidad.

Las representaciones del profesorado revelaron que la EH se asocia a tres dimensiones: vivencial, cognitiva y aplicada. En los procesos de enseñanza y aprendizaje las tres dimensiones deben actuar de manera dinámica e interrelacionadas para considerarse como EH. Es posible vincularla al pensamiento histórico como un aspecto indispensable para el desarrollo de sus competencias y para propiciar el protagonismo histórico del estudiante en la construcción de su conocimiento histórico. Las formas de desarrollar la EH en los procesos de enseñanza y aprendizaje son mediante el uso de recursos de tipo testimonial, la interpretación histórica y mediante metodologías activas orientadas a la participación ciudadana.

Palabras Clave: Experiencia histórica; pensamiento histórico; didáctica; historia oral; protagonismo histórico.

Abstract: This article discusses the results of a qualitative research of the historical experience $(\mathrm{HE})$ as a fundamental aspect of the student's construction of the historical knowledge. The goals of this study were: to define the meaning of the HE from the perspective of the didactic of social sciences, recognize its relationship with the development of the historical thinking and learn how to develop it in the processes of teaching and learning. These goals were explored through the teachers' representations of the concept of $\mathrm{HE}$ from their reflexions of their practice in the classroom when they used the oral history. This study used a qualitative interpretive approach, based in study of case, with a mixed methodology. The data of thirty-three respondents to questionnaires and eight in depth interviews were analyzed.

The results indicated that the teachers' representations of the HE were associated to three dimensions: experiential, cognitive and applied. It was found that in the processes of the teaching and learning these three dimensions have to function in a dynamic and inter-related way to be considered as HE. It is important to note that the HE can be linked to the historical thinking as an essential aspect for the development of the competencies and the facilitation of the student's personal agency in the constructions of the his/her historical knowledge. The ways to develop the HE in the processes of teaching and learning are through the use of the following resources, the use of testimonial, historical interpretation and active methodologies oriented to the civic participation.

Keywords: Historical experience; historical thinking; didactic; oral history; historical protagonist.

SUMARIO: 1. Introducción. 2. Preguntas y objetivo de investigación. 3. Metodología de investigación. 4. La formación en competencias de pensamiento histórico. 5. La noción de experiencia histórica desde las ciencias sociales. 6. Propuesta conceptual de experiencia histórica. 7. Resultados obtenidos. 8. Conclusiones. 9. Referencias bibliográficas.

\section{INTRODUCCIÓN}

Diversas investigaciones en didáctica de las ciencias sociales han señalado una desmotivación de los estudiantes por el aprendizaje histórico, muchas veces considerado como una asignatura irrelevante e inútil para su vida cotidiana (Stearns, 2004; Levesque, 2008; Henríquez, 2009; Plá, 2011; Muñoz y Pagès, 2012; Saiz y Fuster, 2014; Ibáñez, Gillate y Madariaga, 2015). El distanciamiento entre la historia, la historia escolar y la realidad generan el desafío de promover cambios en los 
procesos de enseñanza y aprendizaje. La historia debe dejar de ser considerada un discurso alejado y sin sentido para el alumnado. Es necesario repensar la historia escolar para lograr hacerla próxima, viva y significativa como un conocimiento en constante construcción.

Desde la didáctica de las ciencias sociales se señala que una de las finalidades más importantes es formar el pensamiento histórico para desarrollar de forma progresiva la conciencia histórica. Autores como Pagès (2009), Plá y Pérez (2013) y Soria (2014) mencionan el rol fundamental del profesorado como mediador del proceso de enseñanza y aprendizaje, quien debe predisponer a sus estudiantes a enfrentarse a una serie de retos que les permitan significar la historia, interpretar las fuentes, comprender diversas perspectivas históricas, sintetizar y comunicar la información argumentando sus propios puntos de vista.

Henríquez (2009) señala que el pensamiento histórico «es la manera como internalizamos el pasado en nuestros mecanismos cognitivos y experienciales» ( $p$. 69). Por consiguiente, en el proceso de construcción de los saberes históricos, el estudiante involucra sus propias vivencias, recuerdos, representaciones sociales y saberes escolares. Estos elementos personales deberían ser considerados fundamentales para lograr una apropiación del conocimiento histórico y para favorecer su formación integral como sujeto social. Para Ross (2015) la experiencia es educativa en la medida que los estudiantes incorporan sus vivencias para formar un pensamiento crítico, tomar decisiones y actuar en función de una sociedad más justa e igualitaria.

Esta investigación aborda un campo de estudio muy poco explorado desde la didáctica de las ciencias sociales: la experiencia histórica. La EH ha sido abordada principalmente desde la hermenéutica y la epistemología de la historia por HansGeorge Gadamer y Frank Ankersmit, por lo que son los autores de referencia de este estudio.

La complejidad del concepto y la inexistencia en los debates educativos nos instó a abordar la noción de EH, a partir de reflexiones del profesorado sobre sus prácticas educativas cotidianas y a través de preguntas relacionadas con el uso de la historia oral y/o testimonios como estrategia didáctica. Así, para comprender su significado en los procesos de enseñanza y aprendizaje nos centramos en las representaciones sociales del profesorado, ya que consideramos que sus concepciones, ideología y finalidades influyen en sus decisiones y en los aprendizajes del alumnado (Shulman, 1986). Además, estimamos que la mejor manera de reconocer evidencias de la EH era mediante la historia oral, ya que, como especificación historiográfica, permite que el estudiante construya conocimientos históricos a partir del recuerdo de las vivencias pasadas y, además, desarrolle una metodología activa de aprendizaje.

El interés principal de este estudio es aportar una perspectiva epistemológica que enriquezca los conocimientos sobre la construcción de los saberes históricos 
escolares, específicamente sobre la trascendencia que tiene la EH en la producción de significados históricos. Plá y Pagès (2014) señalan la necesidad de generar investigaciones en didáctica que permitan «vincular los procesos de enseñanza de la historia a explicaciones teóricas más amplias» (p. 33). Entender la relevancia de la EH dentro del proceso de formación de pensamiento puede ayudar a comprender la historia como ciencia social viva, en constante construcción y donde se valide el protagonismo de todos los sujetos históricos incluidos nuestros propios estudiantes.

\section{PREGUNTAS Y OBJETIVO DE INVESTIGACIÓN}

Las preguntas planteadas en esta investigación son: ¿Qué es la EH para la didáctica de las ciencias sociales? ¿Cómo se relaciona la EH con la formación del pensamiento histórico y cómo se puede desarrollar en los procesos de enseñanza y aprendizaje? ¿Qué concepciones tiene el profesorado sobre el concepto al reflexionar sobre sus prácticas de aula y, particularmente, al utilizar la historia oral como estrategia didáctica?

Los objetivos que se desprenden de los anteriores interrogantes son:

1. Definir el significado de EH, su relación con la formación del pensamiento histórico y las formas de desarrollarla en los procesos de enseñanza y aprendizaje.

2. Indagar sobre las representaciones sociales del profesorado sobre la EH a partir de sus reflexiones en torno al uso de la historia oral como estrategia didáctica.

\section{METOdOLOGÍA DE INVESTIGACIÓN}

La población de estudio estuvo compuesta por profesoras y profesores de ciencias sociales de Cataluña. Nos interesó centrarnos en sus representaciones sociales porque son agentes moderadores de los procesos educativos, quienes crean, modifican e interpretan la realidad desde una perspectiva particular e individual. La muestra se fue seleccionando de manera gradual, ya que en un primer momento fue aleatoria y luego se escogieron casos sensibles y de carácter intencional.

Primero, se aplicó el cuestionario como primer instrumento exploratorio a un total de 33 profesores y profesoras de ciencias sociales de Cataluña, de los cuales el $54,5 \%$ son mujeres y un $45,4 \%$ hombres. Esta selección fue de carácter aleatorio siguiendo el criterio por conveniencia según la posibilidad de acceso a los informantes (Flick, 2007). La mayor parte de estos profesores y profesoras tienen más de 20 años de ejercicio docente $(54,5 \%)$ y se han desempeñado principalmente en educación secundaria, bachillerato y formación docente. El 42,4 \% posee grado de licenciatura, el 30,3 \% cuenta con una maestría y un $27,3 \%$ ha realizado estudios 
de doctorado en el área de la didáctica de las ciencias sociales (seis profesores), filosofía y letras (dos profesores) y uno sin catalogar.

Se seleccionó una muestra de carácter intencional para realizar las entrevistas en profundidad (Sabariego, 2004; Flick, 2015). Se escogieron deliberadamente a ocho profesores por su potencial informativo, ya que requeríamos de participantes con conocimientos, experiencia y práctica en actividades de historia oral para que nos aportaran datos relevantes y que accedieran voluntariamente a participar en la investigación. Las ocho personas entrevistadas, el 75 \% son mujeres y el $25 \%$ son hombres, fueron divididas en dos grupos. El primer grupo, lo componen cinco informantes expertos que se caracterizan por tener varios años de ejercicio docente, una trayectoria destacada en proyectos de innovación de historia oral y en su mayoría tienen formación especializada en el área de didáctica de las ciencias sociales. El segundo grupo está compuesto por tres docentes de secundaria que, durante el trascurso de la investigación, estaban realizando proyectos de innovación y actividades de aprendizaje con historia oral. Esta división del profesorado se justifica por los diferentes perfiles académicos que se encontraron y que se consideró que podían influenciar en las reflexiones y respuestas obtenidas.

La metodología de la investigación fue cualitativa de tipo interpretativa y se utilizaron métodos mixtos para el análisis de los datos. El enfoque cualitativo nos permitió "entender el mundo subjetivo de la experiencia humana» (Cohen y Manion, 1990, p. 68), en concreto interpretar las creencias, valoraciones y significados del profesorado sobre la noción de $\mathrm{EH}$. Se utilizaron métodos mixtos en el análisis de los datos, aplicando un cuestionario inicial y posteriormente se realizó una entrevista en profundidad.

Por un lado, el cuestionario contenía preguntas abiertas y cerradas, y se utilizó como instrumento exploratorio para realizar una primera aproximación sobre la realidad estudiada. Para el análisis de los datos se siguió la propuesta de Miles y Huberman (como se citó en Simons, 2011), basado en la reducción en categorías, exposición, conclusiones y verificaciones de los datos. Las preguntas abiertas fueron analizadas a través del contenido latente que nos permitió desvelar significaciones y estructuras ocultas del mensaje (Van der Maner, 1995).

Por otro lado, se utilizó la entrevista para profundizar en aspectos que no fueron posibles de recoger con el cuestionario. El objetivo era analizar los significados y valoraciones que el profesorado le otorga a la EH en el aprendizaje, haciendo reflexiones sobre sus propias prácticas de aula al utilizar la historia oral como estrategia didáctica. Estos datos fueron tratados a través del análisis de aquellos aspectos conceptuales emergentes, pero también otros niveles de mensaje más profundos. Para el análisis se siguió la propuesta de Wolcott (como se citó en Simons, 2011) basados en la descripción, el análisis y la interpretación. Se utilizó el programa Atlas-Ti, el cual permitió generar redes semánticas que reflejan relaciones entre las categorías o códigos obtenidos. 


\section{LA FORMACIÓN EN COMPETENCIAS DE PENSAMIENTO HISTÓRICO}

La enseñanza de la historia tiene como finalidad formar el pensamiento histórico a partir del desarrollo de una serie de procedimientos y habilidades que permiten comprender el pasado, dar sentido al presente y proyectar el futuro (Seixas \& Peck, 2004; Plá, 2005; Pagès 2009; Santisteban, 2010; Santisteban, GonzálezMonfort y Pagès, 2010; Plá y Pérez, 2013; Soria, 2015). El pensamiento histórico es un proceso complejo que requiere del desarrollo de operaciones cognitivas y procedimientos metodológicos propios de la disciplina, pero también involucra otros elementos como la perspectiva cultural, ideológica y posicionamientos del alumnado. Para esta investigación nos situamos en el modelo conceptual de pensamiento histórico de Santisteban (2010), el cual se basa en el desarrollo de cuatro competencias: interpretación, representación, imaginación y conciencia históricatemporal.

La interpretación de las fuentes históricas es considerada como una competencia clave asociada al proceso sistemático de construcción de conocimiento. Posee diversos valores educativos, entre ellos permite un aprendizaje autónomo del estudiante a través del contacto directo con el pasado. Las fuentes deben ser decodificadas mediante la lectura crítica, procedimiento que involucra tanto la extracción de información explícita como la realización de inferencias de mayor complejidad asociadas a aspectos de la literacidad crítica. Siguiendo a González-Monfort, Pagès y Santisteban (2011) la interpretación de fuentes requiere de tres operaciones básicas: a) lectura y tratamiento de documentos o evidencias históricas; b) confrontación de textos históricos con interpretaciones diferentes u opuestas; y c) el proceso de construcción de la historia.

La representación histórica se relaciona con la elaboración de un discurso histórico que evidencia la apropiación del conocimiento del alumnado. Esta competencia requiere de las habilidades de selección de información, como también de la elaboración de explicaciones causales expresadas a través de una trama coherente y argumentada. La narración es una de las principales herramientas de representación, ya que refleja el grado de desarrollo del pensamiento a partir de las formas que se utilizan y organizan las explicaciones históricas, incluyendo personajes, escenarios, hechos históricos, valoraciones o juicios morales (Plá, 2005; Henríquez, 2009).

La imaginación requiere de la empatía para recrear las situaciones y entender la perspectiva y decisiones de los sujetos del pasado. La contextualización permite situarlos en sus códigos, normas y sistema de creencias, a partir del cual es posible realizar opiniones o juicios morales de manera apropiada. El pensamiento crítico es fundamental porque implica valorar, comparar y hacer relaciones del pasado con el presente y mediante el pensamiento creativo es posible imaginar otras posibilidades de futuro (Santisteban, 2010; Anguera, 2012; Yuste, 2017). 
La conciencia histórico-temporal se considera como un aspecto de orden superior y se relaciona con la temporalidad humana que permite relacionar pasado, presente y futuro (Rüsen, 2007). Además, incluye operadores temporales necesarios para gestionar el tiempo histórico como datación, cronología, causalidad, periodización, entre otros (Santisteban, 2005; Santisteban, 2010; Llusà, 2015). Su desarrollo en el aprendizaje escolar es considerado fundamental de la educación para la ciudadanía democrática.

Para que el aprendizaje histórico sea significativo, estas cuatro competencias de pensamiento histórico deberían favorecer la formación integral de los estudiantes tanto desde una perspectiva personal como social. Para Soria (2015) el pensamiento histórico «abre las posibilidades a la formación de individuos mucho más autónomos y empáticos, aspectos que contribuyen a la formación de una ciudadanía vinculada con valores democráticos» (p. 41). El estudiante debe ser capaz de regular sus aprendizajes, para comprender, interpretar e intervenir en las diferentes situaciones de su vida cotidiana (Pagès y Santisteban, 2011).

\section{LA NOCIÓN DE EXPERIENCIA HISTÓRICA DESDE LAS CIENCIAS SOCIALES}

Para entender la naturaleza del concepto $\mathrm{EH}$ es necesario profundizar en los debates epistemológicos realizados por diferentes disciplinas de las ciencias sociales. La noción es utilizada habitualmente por la filosofía y la teoría de la historia y, en menor medida, por la didáctica de la historia, y ha servido para abordar diversas temáticas, concepciones y objetos de estudio (Belvedresi, 2017). Nos situamos principalmente en los aportes de la filosofía con Hans-George Gadamer y desde la teoría de la historia con Frank Ankersmit, porque han realizado reflexiones específicas sobre la $\mathrm{EH}$.

Desde la filosofía

Gadamer concibió la historicidad del sujeto y su EH como aspectos fundamentales en la construcción del conocimiento. Señala que la interpretación es un procedimiento dinámico que se inicia con las ideas previas provenientes de la llamada "experiencia vital y de la vida histórica» (Gadamer, 1995, p. 28). En otras palabras, sostiene que el sujeto experimenta el mundo de manera pre-reflexiva y pre-teórica, y que a través de la percepción del individuo es posible la comprensión de la realidad.

A partir de los aportes de la hermenéutica de Heidegger consideró como principio fundamental que para «la adopción y presunción de verdad de un contenido el hombre mismo tiene que estar en ello» (Gadamer, 1977, p. 430). Por lo tanto, la EH del sujeto originada por sus vivencias y realidad histórica permite la apropiación del 
mundo a través de la comprensión. El carácter histórico de la experiencia responde a la historicidad, es decir, los códigos culturales y el contexto histórico moldean la conciencia histórica influyendo en la forma de interpretar la realidad. Por esta razón y basándose en los aportes de Dilthey, señala que «solo podemos conocer desde una perspectiva histórica puesto que nosotros mismos somos ya siempre seres históricos» (Gadamer, 1993, p. 58).

Su postura fue crítica a la obsesión objetivista del empirismo moderno, por no legitimar la historización de la EH como parte importante de la comprensión. Sin embargo, Gadamer (1977) es consciente de que no siempre las estructuras apriorísticas provenientes de las vivencias permiten explicar aspectos desconocidos, por lo cual, la interpretación es un proceso fundamental que permite acceder a un mejor saber. En este sentido, es posible afirmar que la hermenéutica gadameriana no limita el conocimiento solo a la $\mathrm{EH}$, sino que la considera como un aspecto que enriquece el saber, lo «amplía y lo ensancha a través del auto conocimiento históricoexperiencial» (Domingo, 1993, p. 33).

La $\mathrm{EH}$ no se constituye como un saber estático, sino que se va modificando a partir de la construcción de nuevos significados. Este principio se entiende como la dialéctica de la experiencia gadameriana, la cual plantea que «la experiencia tiene su propia consumación no en un saber concluyente, sino en esa apertura a la experiencia que es puesta en funcionamiento por la experiencia misma» (Gadamer, 1977, p. 432). La interpretación es una acción transformadora de la EH, que no elimina por completo las experiencias pasadas, sino que incorpora ideas nuevas y genera una nueva EH distinta a la anterior.

Desde la teoría de la historia

Para Ankersmit la EH se relaciona con la realidad experimentada del sujeto en el pasado cuya función es permitir «el momento más propio del conocimiento histórico» (Ankersmit, 1993, pp. 8-9). Destaca los aportes historiográficos realizados por Huizinga (como se citó en Ankersmit, 2006a), distinguiendo tres características principales de la $\mathrm{EH}$ : a) son aspectos de la realidad pasada significativos para el individuo; b) genera una sensación histórica que no es posible de producir deliberadamente; $y, c)$ permite la convicción de que se ha establecido un contacto directo y auténtico con el pasado.

Ankersmit $(2005 ; 2008)$ le otorga un carácter sublime a la EH porque considera que tiene valor por sí misma y porque es independiente a la interpretación. Si bien, la $\mathrm{EH}$ del sujeto se genera en un momento histórico específico, el contexto no es determinante en la interpretación de la realidad. Utilizando sus palabras «my thesis is that the undeniable fact that the occurrence of a historical experience is context-bound need have no implications as to the content of that experience» (Ankersmit, 2006a, p. 116). A pesar de que la EH no tiene 
una pretensión cognitiva, posee una utilidad fundamental en la comprensión, porque entrega una sensación histórica de contacto directo con el pasado desde el presente. Es posible relacionarla con una «sensation effects a fissure in the temporal order so that the past and the present are momentarily united in a way that is familiar to us all in the experience of déjà vu» (Ankersmit, 2006b, p. 140).

Es interesante destacar el cuestionamiento que realiza sobre: "What is the function of historical experience in historical practice?» (Ankersrmit, 2006a, p. 120). Aborda este interrogante señalando que la disciplina histórica se genera por intelectuales que construyen conocimientos sustentados en evidencias fiables para que sean validados o rebatidos por otros. Dentro de los fundamentos historiográficos, la $\mathrm{EH}$ no debe ser considerada ni parte de la teoría ni como argumento de persuasión, sino como una herramienta que permite un posicionamiento del historiador sobre el pasado o como una base para cuestionar, confirmar o desafiar otros discursos históricos. Por estas razones, su conclusión más importante es que si bien la $\mathrm{EH}$ no es necesaria para convertirnos en historiadores de excelencia, otorga una riqueza y autenticidad única a las producciones históricas, porque genera conocimientos auténticos y significativos sobre cómo experimentamos, interpretamos y sentimos el pasado.

Desde la didáctica de las ciencias sociales

Autores como Rüsen (2001), Wineburg (2001), Henríquez (2009), Santisteban (2010), Santisteban et al. (2010), González-Monfort et al. (2011), Mattozzi (2011) y Ross (2015) han aludido al concepto, señalando que la EH puede ser un instrumento de motivación para el aprendizaje o como un elemento esencial en la formación de competencias de pensamiento histórico.

El proceso de interpretación de fuentes «favorece el desarrollo de la competencia de la interpretación histórica, pero también la incorporación de la experiencia histórica» (Santisteban, 2010, p. 49). Este proceso incluye aspectos personales, culturales, históricos del alumnado en el momento de hacer una lectura crítica dándole un sentido particular a sus formas autónomas de comprender. Además, Santisteban et al. (2010) sugieren que el trabajo con fuentes debe realizarse en función de problemas históricos a partir de los cuales el alumnado «pone en juego su experiencia histórica, para el desarrollo de la competencia histórica» (p. 120).

La comprensión empática requiere de la capacidad de razonamiento y de la contextualización para dar sentido a las acciones del pasado, pero también involucra una disposición del alumnado para comprender los diferentes puntos de vista y tratar de ponerse en el lugar de otra persona. La investigación de Davison (2012) señala que la empatía histórica involucra aspectos cognitivos 
y afectivos, "It is cognitive because it requires thinking about how pieces of evidence fit together. It is affective because it attempts to imagine what an historical character might have felt» (p. 13). Sin embargo, es importante destacar que se requiere del pensamiento crítico para realizar juicios morales históricos adecuados.

En cuanto a la representación histórica, los aportes de Rüsen (1992) han permitido entender la importancia de la narrativa para dar sentido al pasado "haciendo efectiva una orientación de la vida práctica presente por medio del recuerdo de la realidad pasada» (p. 29). El contenido de la narrativa es la EH y la entiende como la habilidad para tener experiencias temporales diferenciando el pasado del presente, como una especie de sensibilidad histórica. Salazar (como se citó en Santisteban, 2010) considera que una narrativa debe responder «a un problema planteado por la realidad, en la cual se muestra la experiencia humana y no solo conceptos abstractos» (p. 4).

La EH actúa como un importante eje articulador de la temporalidad humana. La conciencia histórica es un proceso mental que requiere pensar y pensarse en el tiempo, desde la relación pasada, presente y futura (Pagès, 2003). La memoria es el instrumento de representación del pasado a partir del recuerdo de experiencias humanas. El presente es el lugar en el cual se sitúa el sujeto para interpretar el pasado e imaginar sus expectativas futuras. En definitiva, la importancia fundamental de la conciencia histórica es que permite comprendernos como sujetos históricos capaces de reflexionar temporalmente y usarla «como medio de orientación en la vida diaria» (González, 2006, p. 24).

Por lo tanto, la EH es un elemento mencionado en las teorías didácticas sobre la formación del pensamiento histórico. Sin embargo, son inexistentes las investigaciones que permitan precisarla y definirla en los procesos de enseñanza y aprendizaje o que permitan desarrollarla de manera intencionada en los procesos de significación histórica.

\section{PROPUESTA CONCEPTUAL DE EXPERIENCIA HISTÓRICA}

En base a los referentes teóricos mencionados y a partir del análisis de los datos de esta investigación, se propone el siguiente modelo conceptual de EH basado en tres dimensiones: vivencial, cognitiva y aplicada. 
Figura 1. Modelo conceptual de experiencia histórica

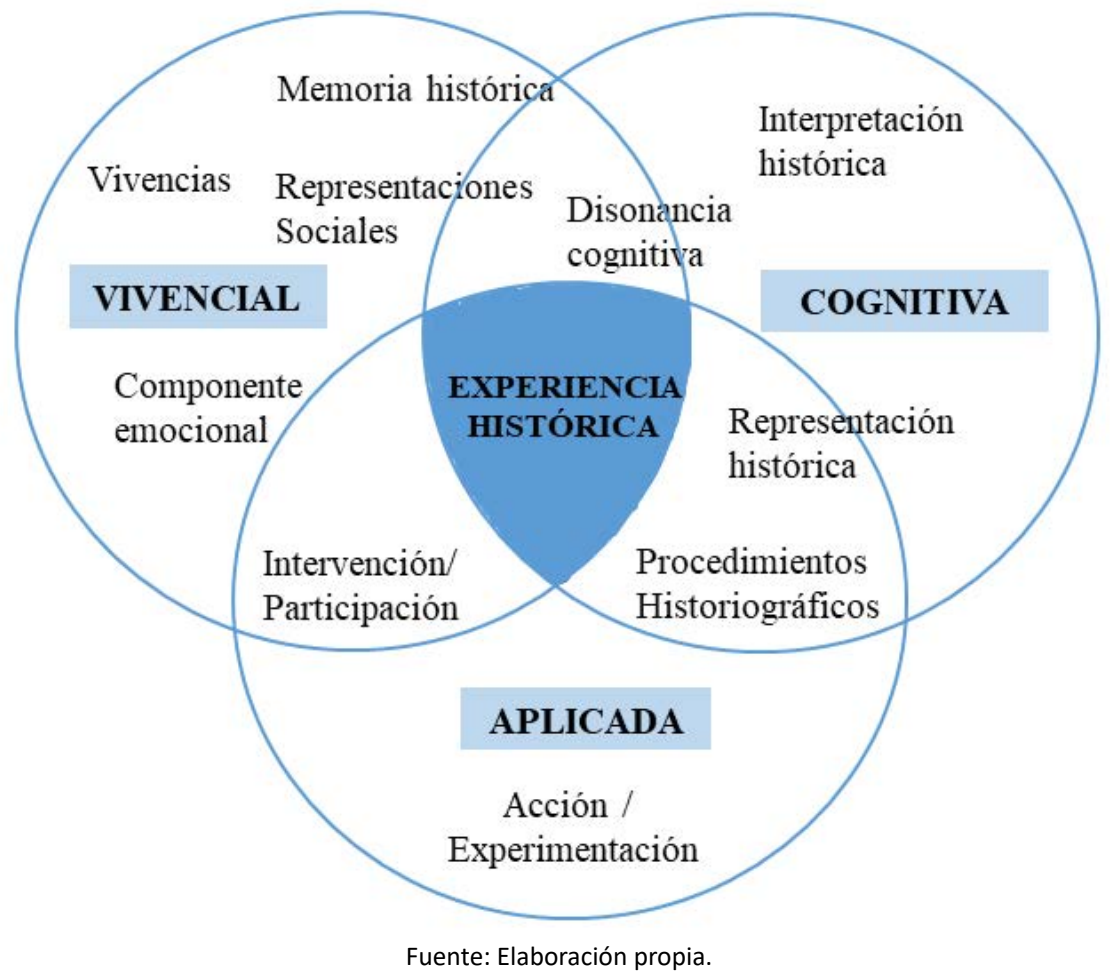

Por un lado, la EH vivencial se asocia con un saber cotidiano e inmediato obtenido a través de la realidad vivida, el cual permite disponer de un cuerpo propio e individual de conocimientos y habilidades, que puede ser convertido en algo objetivo a través del razonamiento consciente (Cohen y Manion, 1990). Las experiencias vividas, ya sean cotidianas o excepcionales, son traídas al presente y relaboradas a través de la memoria histórica, la cual utiliza el recuerdo para producir determinadas representaciones sociales, emociones y sensaciones históricas. Las representaciones sociales son un conjunto de contenidos, ideas y operaciones lógicas con las que el individuo comprende la realidad social y su entorno (Moscovici, 1979). En el aprendizaje escolar permite que el estudiante asocie algún aspecto desconocido a construcciones mentales conocidas o familiares.

Para Ross (2015) las experiencias pasadas son educativas en la medida que el individuo las utiliza para poder formar un pensamiento crítico, tomar decisiones y actuar en función de una sociedad más justa e igualitaria. Entiende la educación como un todo, como un «critical knowledge of everyday life» (p. 145), en el cual el pasado personal, familiar y el contexto social deben ser utilizados en la educación escolar como un elemento clave, ya que los individuos crean sus opiniones en función de sus propias auto-interpretaciones. 
Por otro lado, la EH cognitiva se relaciona a un acto deliberado de razonamiento, reflexión e interpretación que puede ser considerado como otra forma de experimentar el mundo (Van Manen, 2003). Se asocia al saber escolar y a la construcción del conocimiento histórico mediante la interpretación y la construcción de significaciones o representaciones históricas. Además, la adquisición de nuevos saberes puede transformar, confirmar o adaptar las representaciones sociales iniciales del alumnado a través de un proceso denominado como disonancia cognitiva (Dalongueville, 2003).

Como es una construcción intelectual humana, la interpretación, el análisis y apropiación histórica se encuentran impregnados de subjetivaciones, representaciones o juicios y prospecciones. Cada estudiante interpreta las huellas o documentos del pasado a partir de su propio marco de referencia, posición ideológica, intelectual y cultural, por lo cual es inevitable que en este proceso se incorporen las vivencias personales. Como lo plantean Santisteban et al. (2010), uno de los valores educativos de la enseñanza de la historia a través de las fuentes es que favorece la riqueza de las experiencias y permite adquirir progresivamente habilidades y conceptos históricos.

Finalmente, la EH aplicada se relaciona con el proceso de trascendencia del ser histórico mediante la acción, experimentación, intervención o participación y el desarrollo de procedimientos historiográficos. Como dimensión de carácter más compleja, requiere de acciones deliberadas del alumnado en la construcción de aprendizajes históricos, así como también de propuestas sociales para el cambio y construcción de futuro. Además, permite formar en conciencia histórica, como finalidad última en la enseñanza de la historia.

Es necesario que el estudiante someta sus saberes cotidianos a un proceso reflexivo, crítico y creativo que le permita formar su pensamiento social, para que pueda tomar decisiones efectivas y enfrentar el mundo complejo en que vivimos. Debe experimentar, a través de decisiones, producciones y prospecciones su condición de sujeto histórico constructor de futuro. Esto responde a lo planteado por Pagès y Santisteban (2014), cuando afirman que el conocimiento social se construye «a partir de actividades de todo tipo y su aprendizaje estará condicionado por las experiencias personales de cada individuo» (p. 25).

\section{RESULTADOS OBTENIDOS}

Los instrumentos utilizados en esta investigación han permitido analizar las concepciones e ideas del profesorado sobre la $\mathrm{EH}$ a partir de reflexiones realizadas sobre sus propias prácticas de aula y en función del uso y valor de la historia oral como estrategia didáctica. A partir de estos datos, hemos podido aproximarnos a la comprensión del concepto, relacionar la EH con la formación del pensamiento 
histórico y, por último, reconocer estrategias que permitan desarrollarla en los procesos de enseñanza y aprendizaje.

Noción de EH en el aprendizaje histórico

La noción de $\mathrm{EH}$ es abordada directamente solo en una de las preguntas de la entrevista: Cuando menciono este concepto de "experiencia histórica" ¿qué es lo que te sugiere o a qué crees que me estoy refiriendo? La complejidad del concepto se reconoce en las respuestas obtenidas, ya que el profesorado evidenció cierta incomodidad al elaborar sus justificaciones. Sin embargo, se distinguieron tres dimensiones en sus explicaciones: vivencial, cognitiva y aplicada.

La dimensión vivencial fue señalada por una informante experta y una profesora en ejercicio. Para la profesora $\mathrm{P} 10$ la $\mathrm{EH}$ se relaciona a «que vivas tú en tus sentimientos y que te afecten (...) con la historia oral te explican cómo bombardearon, pues que su abuelo o su bisabuelo estaba allí». Para la profesora P3 «la idea de experiencia histórica, es esta idea de yo he vivido un momento histórico determinado, es mi propia experiencia de este hecho que ha sucedido».

La dimensión cognitiva fue señalada por dos informantes expertos, quienes señalan la interpretación de fuentes y a la construcción de significados históricos. Para P1 «la experiencia histórica es como vivir la historia. Como no tenemos la máquina del tiempo creo que la única manera es a través de la interpretación histórica que son las fuentes». Para P2 la EH se relaciona al discurso histórico, al señalar que «¿Experiencia histórica? pues no lo sé. Será la experiencia que él tiene de la historia, de lo que es la historia para él».

La dimensión aplicada fue mencionada por dos informantes expertos y dos profesores en ejercicio, que consideran que la EH se desarrolla a través de metodologías activas y mediante la participación del alumnado en sociedad. Las metodologías activas son señaladas por P14 cuando plantea que «me suena un poco como algo de aventura. El concepto experiencia me suena como recrear algo, como si debiese de hacer algo como una especie de teatro inmersivo o alguna cosa así». La profesora P33 la relaciona con «juegos de simulación, pueden ser un instrumento para tener experiencia histórica de la dramatización, los juegos de roles, de ponerte en el personaje». Para los otros dos profesores la EH posee una relación directa con el protagonismo del alumnado como sujeto histórico y social. Para P26 conlleva la intervención social al plantear que es «cómo tú intervienes en tu ciudad, en tu ámbito no estrictamente privados, sino un poco más público, tú intervienes. Entonces haces historia e intervienes en la historia. Por lo tanto, es llamar a la gente a la participación, a la actividad política, social y cultural. Es decir, a intervenir. Claro, tú tienes que construir tu experiencia de manera que sea útil a los demás». El docente P4 plantea que es la forma de «ser consciente de lo que está pasando forma parte de la historia (...) Y también es una manera de hacer preguntas de futuro para que 
sean conscientes de cuál es el presente y qué actitud han de tener en el presente». Esta reflexión evidencia una estrecha relación de esta categoría con el desarrollo de la conciencia histórica, la cual permite que la comprensión del pasado permita entender la realidad social y proponer alternativas hacia el futuro.

Finalidades didácticas de la historia oral

Los principales propósitos educativos de la historia oral destacados por el profesorado fueron: la reconstrucción histórica, la interpretación histórica y el proceso metodológico. Se considera que estas tres finalidades tienen una estrecha relación con las tres dimensiones de $\mathrm{EH}$.

Gráfico 1. Finalidades didácticas de la historia oral

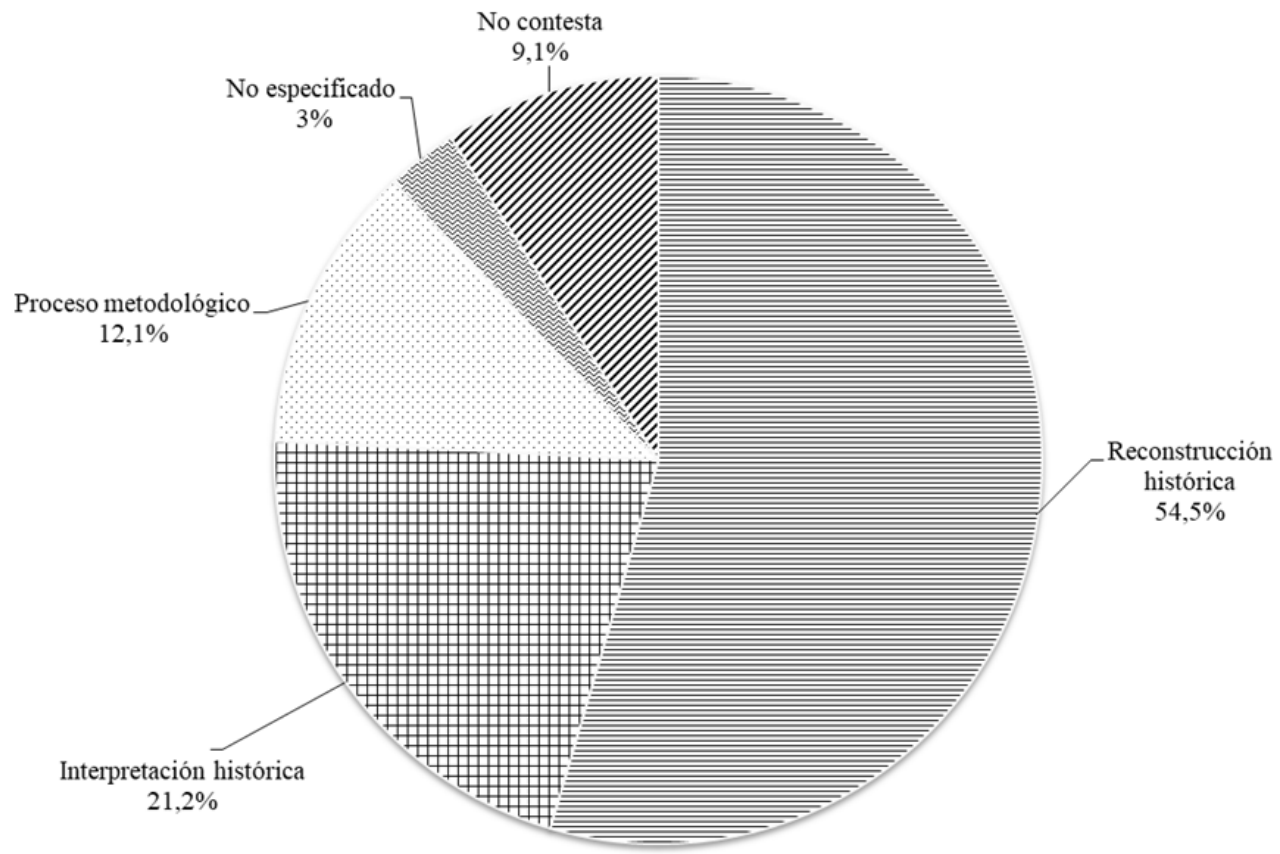

Fuente: Elaboración propia

La mayor parte del profesorado $(54,5 \%)$ señaló como finalidad de la historia oral la reconstrucción histórica de las vivencias pasadas. Esta categoría incorporó propósitos relacionados con la explicación o ilustración de los contenidos a partir de las vivencias y representaciones transmitidas en los testimonios orales. La rei- 
vindicación de la memoria posee una importancia fundamental para comprender el pasado y para otorgarle protagonismo a los diversos sujetos históricos. Así lo señala la profesora P6 «reconstruïm la història a partir dels relats dels que han format part de la història». Además, el componente emocional y afectivo es señalado como un aspecto que favorece aún más los aprendizajes. P14 señala que: "yo creo que las emociones nos ayudan a imprimir la historia en nuestro cerebro, a grabar a fuego. Y cuando a mí una historia de la guerra me la está explicando alguien que yo quiero, y me están explicando su sufrimiento o lo que se rio el día que se burló de no sé quién o se escapó de no sé cuántos, hace que sea mucho más real».

La segunda finalidad didáctica fue la interpretación histórica (21\%). Esta categoría incluye la lectura de la fuente oral, la contextualización, el contraste entre memorias divergentes y de diversas fuentes históricas. La profesora P2 señala que su actividad buscaba "analitzar la fiabilitat de la font per tal de copsar la informació que ens dona realment, més enllà de la que ens ofereix la seva resposta o explicació oral. I veure com els mateixos fets poden ser explicats de diverses maneres que es poden complementar però que, de vegades, poden ser fins i tot contradictoris».

Finalmente, el 12,1 \% del profesorado consideró como objetivo desarrollar el proceso metodológico de la historia oral. Esta estrategia incluye la realización de entrevistas, elaboración de hipótesis y la construcción archivística de la fuente oral. Para la profesora P15 su actividad se centraba en realizar la «entrevista y registro de voz de personas mayores que han vivido ciertos episodios de nuestra historia contemporánea y que nos dan su testimonio». El profesor P28 señala que la historia oral otorga la posibilidad de "generar un documento para su archivo personal y familiar. Les pido que lo guarden como un tesoro y que, el día de mañana, se lo enseñen a sus hijos para que estos conozcan a sus bisabuelos y tengan una explicación directa de cómo sus familiares y amigos vivieron el periodo. También es un recuerdo que guardan con mucho cariño, teniendo en cuenta que sus abuelos ya son mayores».

Aportes del aprendizaje histórico para la formación del estudiante

Al reflexionar sobre el aprendizaje histórico y el aporte de la historia oral para la vida del estudiante, la mayor parte del profesorado mencionó la comprensión del presente. También surgieron visiones asociadas a la construcción de futuro, al desarrollo del pensamiento crítico y para el reconocimiento del protagonismo histórico del alumnado. 
Gráfico 2. Aportes del aprendizaje histórico al estudiante

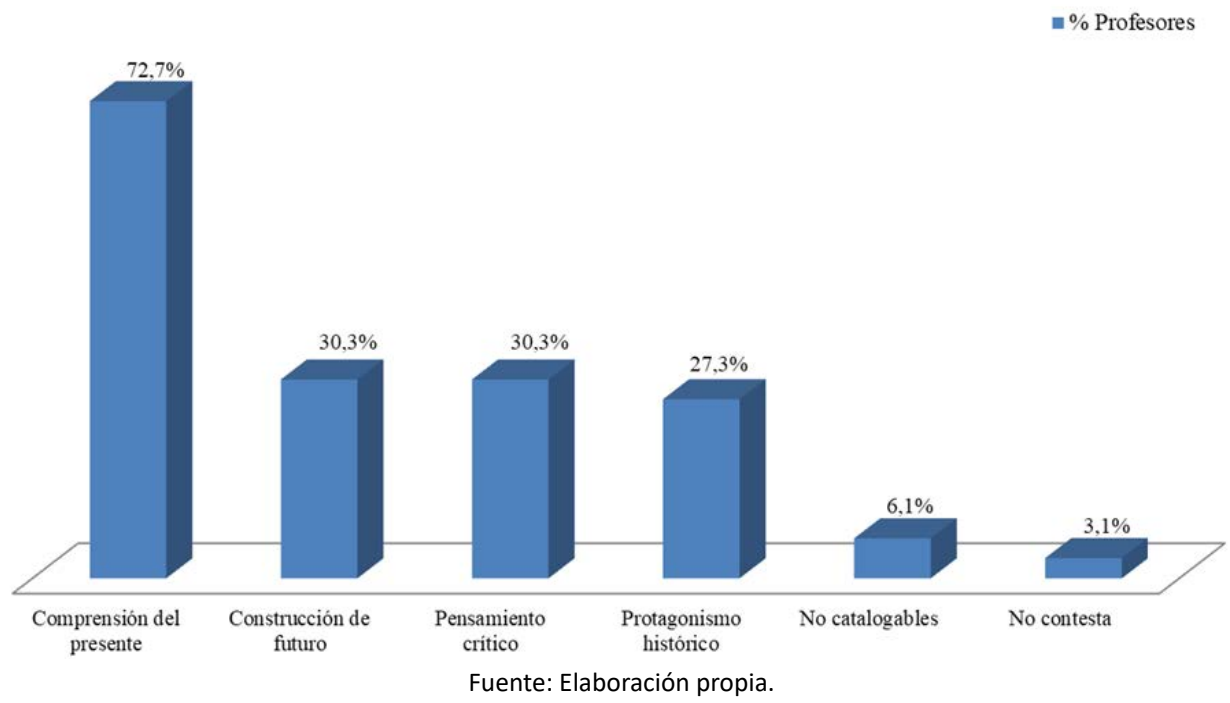

La comprensión del presente fue señalada por 24 profesores que corresponde al $72,7 \%$ del total de la muestra. Se considera que el aprendizaje histórico otorga las herramientas necesarias para entender el mundo actual y su propia realidad cercana y personal. La perspectiva personal es señalada por P26, que considera que «los conocimientos históricos aportan un contexto para poder interpretar la vida cotidiana». Y desde un ámbito global P17 señaló que "el aprendizaje histórico permite comprender la complejidad de los problemas sociales relevantes del presente en su causalidad y ver su dimensión estructural para facilitar la resolución de conflictos». La comprensión de lo local y lo global es señalado por P4 en la entrevista cuando plantea que:

Yo siempre pienso lo mismo, nuestro objetivo es conectar a nuestros alumnos con su entorno, es lo más importante que se conecten con su entorno. Si ellos no son capaces de entender que hay conflictos en Oriente medio, que hay países pues que tiene unas dificultades ecológicas o pues no estamos haciendo nada. Nuestro objetivo es que se relacionan con su entorno, entonces hay que empezar con su entorno más próximo que es Barcelona, después iremos a Cataluña, España, Europa y después vamos con el mundo.

La construcción de futuro fue señalada por 10 profesores (30,3 \% del total de la muestra), que lo relacionan con la toma de conciencia sobre el futuro por parte del alumnado, como lo señala P19 cuando plantea que el aprendizaje histórico «nos 
proporciona "pistas" para afrontar el futuro de una forma mejor» y P24 señala que la construcción de futuro permite "legar un mundo más justo y sostenible a las generaciones futuras». Desde la perspectiva personal, P1 señala que el aprendizaje histórico es "la base para la construcción de su futuro» y el profesor P5 considera que «nos permite desarrollar la conciencia histórica, que nos permitirá construir nuestro futuro».

Un total de 10 profesores, que corresponde al 30,3 \%, señalaron que el aprendizaje histórico aporta al estudiante herramientas para pensar críticamente sobre la realidad. Esta cualidad es de gran aporte para su vida diaria, ya que le permite cuestionar y analizar la información a partir de lo cual es posible tomar decisiones argumentadas. P27 señala que el aprendizaje histórico le permite leer en profundidad la información para evitar manipulaciones, considerando que los estudiantes:

(...) aprenden a preguntar: qué, por qué, dónde, cuándo, quién. Si se plantean preguntas sobre el pasado, aprenden a plantear preguntas sobre la actualidad y la ven desde un punto de vista crítico. Si aprenden a entender y a interpretar documentos históricos (tablas de datos, mapas, gráficos, noticias de prensa, documentos orales) aprenden a interpretar y a entender la información que hoy día les bombardea desde diferentes fuentes (TV, internet, redes sociales) y las miran con ojos críticos. Por ejemplo, se preguntan por qué sobre un mismo hecho hay versiones diferentes según el medio de comunicación que consultan. Se preguntan a qué responde esa diferencia, etc.

P10 considera que las actividades de historia oral deben proyectar la memoria histórica al presente, mediante el cuestionamiento de situaciones actuales, por ejemplo, en cuestiones socialmente vivas o sobre sus responsabilidades ciudadanas «Ves que ellos también se posicionan y les ayudas a ser más críticos (...) y les ayuda también a opinar y en algún momento también a tomar decisiones. Yo siempre les digo bueno, dentro de poco tendréis que votar y, por tanto, tenéis que saber qué y buscar la información. Es un deber como ciudadanos».

El protagonismo histórico es considerado otro de los aportes del aprendizaje de las ciencias sociales. Se considera que utilizar ejemplos concretos de participación es fundamental para formar ciudadanos críticos y activos. Un total de 9 profesores (27\% de la muestra) consideraron que usar testimonios reales favorece el reconocimiento por parte del alumnado, como agente constructor de conocimiento y como un sujeto social. Esta perspectiva se enfatiza en la entrevista de la profesora P2, quien considera que aprender desde la realidad cercana permite mostrar que "la historia no es algo lejano, algo puramente teórico o un ejercicio intelectual, sino que es algo que afecta a las personas. Que la historia la hacen las personas y la padecen las personas, la viven. Entonces se encuentran inmersos dentro de esta historia y forman parte de ella. Y esto les involucra y esto es lo que para mí es más 
importante. Y les hace ver también esta parte personal que las personas la viven, la sufren».

Además, es posible tomar conciencia de que las acciones presentes generan transformaciones y permiten construir el futuro. La responsabilidad social de los sujetos históricos se evidencia en la respuesta de $\mathrm{P} 22$, quien señala que la historia oral "ayuda a que el alumno pueda verse como sujeto histórico». La actividad de la profesora P33 consistió en entrevistar a personas que pertenecían a diferentes asociaciones de vecinos, lo cual contribuye a mostrar ejemplos reales de protagonismo histórico y ser conscientes que «lo que aquella persona les contaba, no era una cosa particular, sino que esta persona estaba trabajando para el bien común, para que [la ciudad de] Cornellá se transformara. Entonces claro, el enlace entre la acción de una persona, el testimonio de una persona, con lo que supuso para la colectividad aquella acción, como la de otros muchos, era muy importante».

Relación de la EH con la formación del pensamiento histórico

Las reflexiones del profesorado en torno a la historia oral han permitido reconocer vínculos importantes entre la $\mathrm{EH}$ y las competencias de pensamiento histórico. La historia oral es considerada como una estrategia activa que facilita la construcción de un discurso histórico de carácter autónomo e inclusivo. Por ejemplo, P23 hace referencia a «la posibilidad de construir ellos el conocimiento como alumnos». Además, permite concebir una historia más humana y validar el protagonismo histórico de la gente común. La profesora P14 reflexiona en la entrevista que «la actividad a estas alturas es guay porque ya ellos comienzan a formarse su opinión de la historia a partir de este elemento, no es una cuestión que les viene cuando lo tiene súper cerrado y entonces les cambia la mentalidad directamente les ayuda a formar su opinión sobre la historia».

Un total de 13 profesores, que corresponde al 39,4 \%, consideraron que la historia oral requiere de la interpretación crítica de su fuente para poder analizar la subjetividad de la memoria histórica. Así lo explica P3 cuando menciona la posibilidad de que el estudiante compare distintos testimonios del mismo hecho histórico y de "comprobar cómo la memoria se "reinventa" y no es algo que quede permanentemente fijado. La posibilidad de percatarse de cómo se puede construir historia a partir del contraste de testimonios, documentos, vestigios, etc. y con lo "ya escrito", la historiografía».

La subjetividad es entendida por algunos profesores como un aspecto constituyente de la interpretación y de la disciplina histórica. Por ejemplo, la profesora P14 señala que «la historia oral, como muchas otras fuentes de información no es objetiva. Se puede considerar como una desventaja, aunque si es compartida con otras fuentes y si se es consciente de ello, no tiene por qué ser un problema». Por 
esta razón el profesor P4 señala que el proceso de contraste es fundamental, y los estudiantes "han de contrastar que todo eso que dicen que es realidad, pues con fotos, videos, imágenes, donde se vea que dicen "pues nosotros jugamos a este juego", pues ilustrarlo, y partir de allí sacar unas conclusiones». Las representaciones sociales son fundamentales para el proceso interpretativo o como lo plantea P33 «el punto de vista del alumno es clave, ya que interviene a la hora de juzgar y de interpretar lo que está viviendo aquella persona o lo que le está explicando aquella persona».

La comprensión empática fue mencionada por 12 profesores, que corresponde al 36,4 \%. Esta competencia se asocia a la capacidad de dar sentido a las vivencias del pasado, lo cual requiere de una disposición del alumnado para comprender los diferentes puntos de vista y tratar de ponerse en el lugar de otra persona. Para P11 «la proximidad de los testimonios permiten que el alumnado empatice más con la historia». Además, el componente emocional es mencionado por el 30 \% del profesorado, destacando los vínculos, sentimientos y afectos como una de sus principales ventajas de la historia oral. Por ejemplo, P15 menciona los dos ámbitos de la empatía (cognición y emoción) señalados por Davison (2012), cuando plantea que «la proximidad (el hecho de sentir a los protagonistas históricos en primera persona, les aproxima a los acontecimientos), empatía (emocional y cognitiva)». Sin embargo, la contextualización es fundamental, como lo señala P2:

Hay unas cuestiones que se debían de trabajar antes y mucho. Lo primero que siempre les decía a los alumnos: no puedes ir a hacer una entrevista si no conoces el tema. Había que familiarizarse con el tema, un poco por respeto a la persona entrevistada, pero también para aprovechar bien la entrevista, porque si no le haces preguntas muy generales y no le puede sacar todo el beneficio a esta persona. Por tanto, había que ir bien preparado.

En cuanto a la representación histórica, la profesora P14 señala que sus estudiantes debían realizar explicaciones propias sobre lo aprendido con las fuentes orales. Para ello, les sugiere «escoger las partes para explicar los testimonios. Tú seleccionas la información y lo haces de una manera que estas explicando como una especie de cuento, un cuento real, pero es una narración que tú haces de una historia. Tú has hecho una entrevista, que es documentación, tú te has documentado y ha sacado una información y ahora lo que buscas es una manera de transmitirlos».

Finalmente, la $\mathrm{EH}$ es mencionada por el profesorado como un aspecto fundamental para hacer relaciones temporales entre pasado, presente y futuro, es decir, para la conciencia histórica. Para P1 considera que abordar aspectos de la vida cotidiana del alumnado favorece el desarrollo de esta competencia: 
Ver y escribir su historia personal, su historia de vida desde su nacimiento hasta ese momento, pero ver las perspectivas de futuro es otra forma de formar conciencia histórica (...). Pero proyectar de cara al futuro es una cosa que me gusta hacer mucho. Una vez hemos visto qué pasa en el pasado, qué está pasando en el presente y proyectar una posibilidad de futuro. En el tema de Cataluña, por ejemplo, lo que ahora nos mueve cada día aquí en Cataluña, pues más de una vez lo hemos proyectado porque ellos me preguntan ¿y qué pasará? Pues no lo sé, no sé qué pasará. Pero vamos a ponerle lógica vamos a ver qué ha pasado en casos similares, vamos a poner una lógica histórica y vamos a proyectar. Quizás nos equivoquemos, pero vamos a hacerlo con un sentido histórico y lo hacemos con muchas cosas. Creo que ese elemento también es central.

Formas de favorecer la EH en los procesos de enseñanza y aprendizaje

Los profesores valoraron diferentes estrategias a partir de la pregunta: ¿Cómo podemos hacer que el alumnado se sienta parte de la historia? Enumera (ordena) del 1 al 10 los siguientes enunciados (siendo 1 el más importante y 10 el menos importante) según las estrategias que te parecen efectivas para la experiencia histórica del alumnado. Esta pregunta no fue contestada por todo el profesorado. Por lo que, en vez de 33 respuestas, solo se obtuvieron 26. Los resultados se muestran en el siguiente gráfico:

Gráfico 3. Valoración de las estrategias

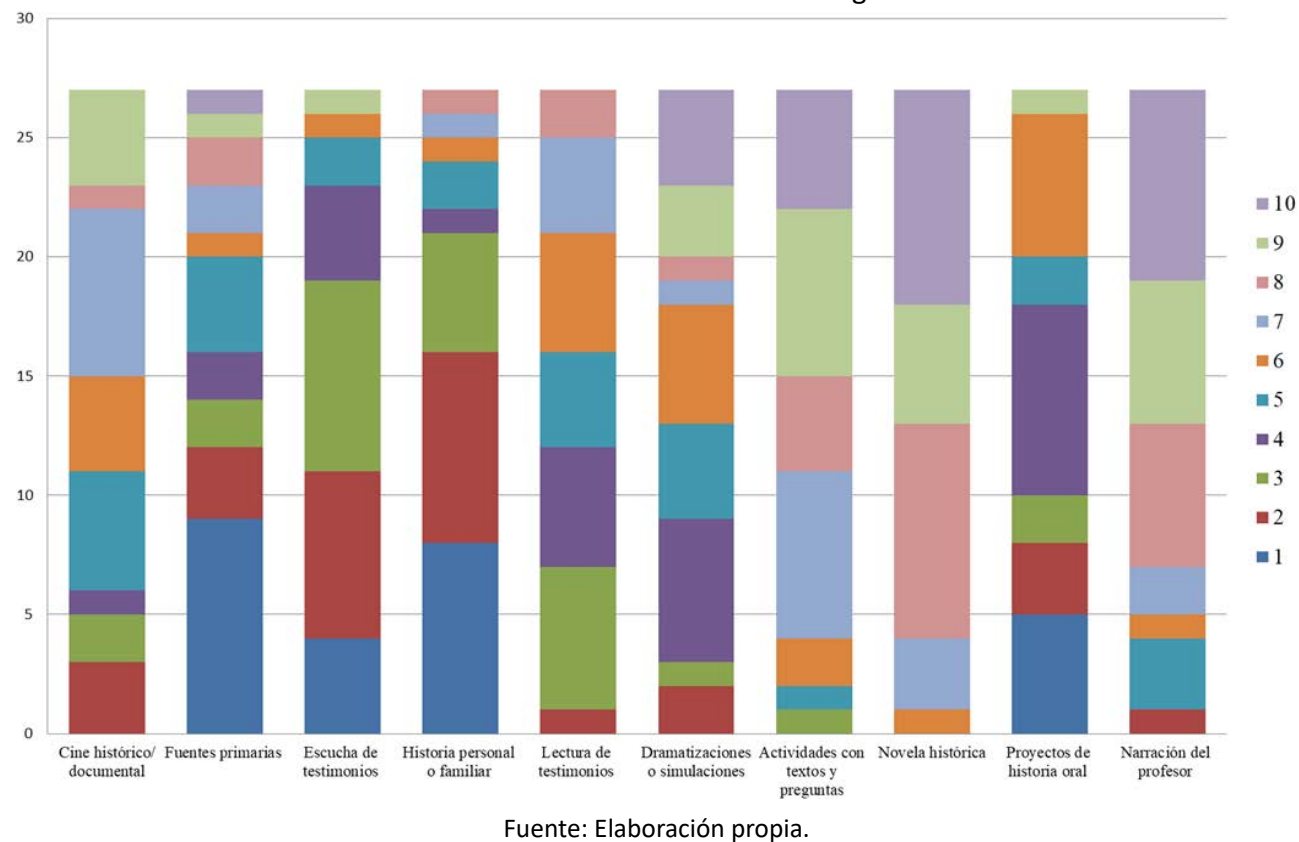

Fuente: Elaboración propia. 
Del gráfico anterior se puede observar que las estrategias más valoradas son las fuentes primarias, la historia personal o familiar, escuchar testimonios y la historia oral. Por ejemplo, para P30 la interpretación de diversas fuentes es fundamental para el desarrollo del pensamiento crítico, aunque considera importante combinarla con otras, ya que mientras «mayor pueda ser la diversidad de estrategias para entender e interpretar el pasado y el presente personal y de la sociedad en que vivimos, amplias los "puntos de miras" y también te ayuda a ser más consciente y más crítico a lo largo de la vida». Las estrategias de carácter vivencial son consideradas relevantes por la profesora $\mathrm{P} 14$, porque permiten «fomentar que se pongan en la piel de los otros colectivos y exploren opciones diferentes a las que tomarían normalmente».

Las estrategias menos valoradas son la narración del profesor, actividades de texto y preguntas, y la novela histórica. P5 considera que la narración del profesor "permite trabajar diferentes aspectos», mientras que para P14 la novela histórica «sirve para complementar y estructurar lo que trabajamos con las otras estrategias".

Al justificar las valoraciones realizadas, es posible reconocer, por un lado, que el profesorado asocia el concepto de EH a aprendizajes significativos y, por otro lado, que considera tres tipos de estrategias para fomentar la $\mathrm{EH}$ : recursos testimoniales, procesos cognitivos y metodologías activas.

Gráfico 4. Estrategias para favorecer la $\mathrm{EH}$

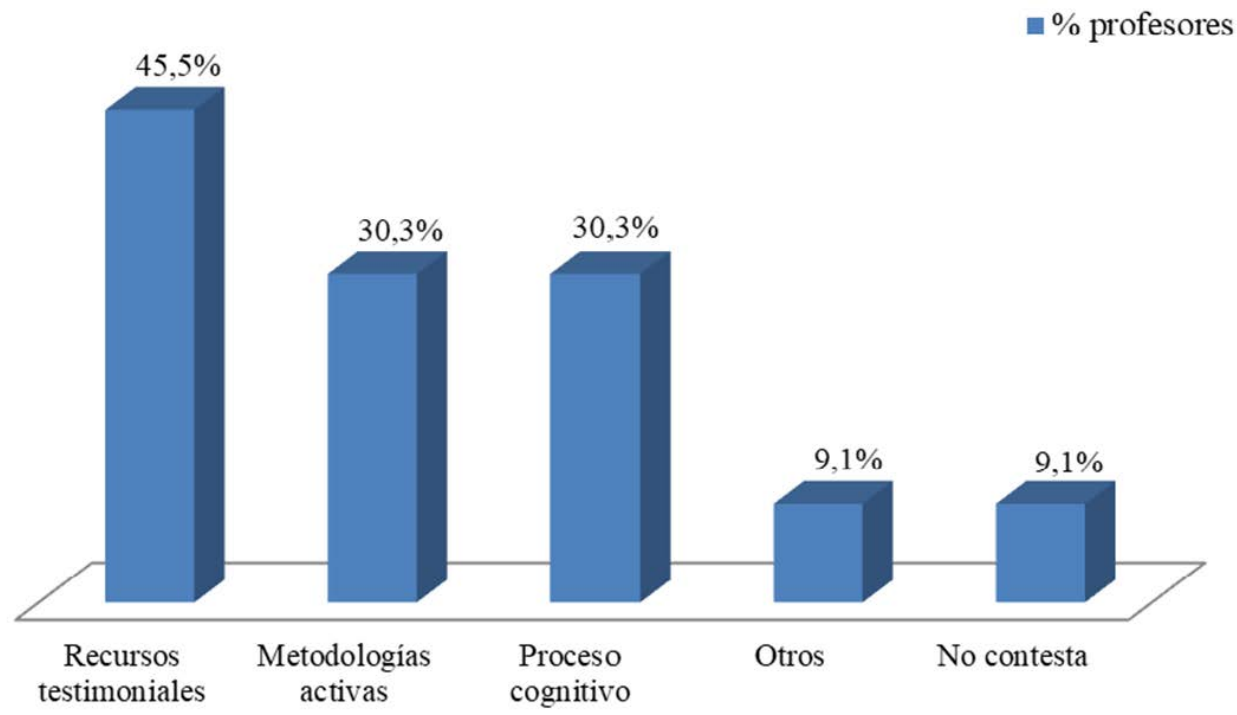

Fuente: Elaboración propia. 
Los recursos testimoniales son considerados como la principal estrategia para desarrollar la EH del alumnado. Un total de 15 profesores $(45,5 \%)$ consideran que el carácter vivencial favorece la motivación del aprendizaje, la competencia empática y genera aprendizajes significativos. Por ejemplo, P17 considera que al «aportar testimonios al aula o proyectos de historia oral creados por los estudiantes, el grado de motivación aumenta de forma relevante». La profesora P22 considera que «los testimonios directos o indirectos de los hechos ayudan a los alumnos a vivenciar la historia y a ponerse en la piel». La conexión con el entorno y la realidad del estudiante es señalada por P16, quien dice que «el alumnado aprende más (y está más interesad@) cuando se empieza con algo que el/ella ya conoce, como la realidad de su familia o de alguien muy cercano». Se destaca la respuesta de P26, quien prioriza aquellas actividades que «permiten conectar con las propias vivencias de los estudiantes». En la entrevista en profundidad esta profesora reflexiona sobre los beneficios de la historia oral y señala que «intentamos hacer esta historia con cosas que ellos pueden tener tangibles de su vida. $Y$ a veces es muy difícil. Pero no solo una conexión de hechos, unos hechos que se relacionan, que tienen unas causas que ahora se relaciona con su vida».

La segunda estrategia se asocia a metodologías activas. Un total de 10 profesores, que corresponde al 30,3 \% del total, considera que el estudiante se puede sentir parte de la historia, a través de estrategias didácticas activas y centradas en el estudiante. Por ejemplo, P15 priorizó en función de «toda actividad que tenga como protagonista al alumnado, será de mucha más significatividad para su aprendizaje histórico». La profesora P2 valora positivamente la historia oral porque permite realizar «projecte de recerca realitzat per alumnes, sota la guia d'un docent, permet que treballi i contrasti diferents tipologies de fonts i aprengui història fent d'historiador/a. (entenc un projecte de recerca ampli)». En la entrevista profundiza sobre este aspecto y señala que:

Yo creo que los alumnos, cuando hacen un trabajo de este tipo, se lo pasan muy bien en general, aprenden bastante, se involucran mucho y en general las valoraciones son muy positivas (...). Yo creo que incorporan mucho más el modelo del investigador que tienen ellos más relacionados con solucionar un enigma, un caso. Los modelos que tenemos de investigador ahora son los casos policiacos, novelas. Entonces en la medida que les puedes poner una cuestión que tenga que resolver, enseguida tiene una parte también lúdica y son capaces entonces de trabajar un montón, de involucrarse.

La tercera estrategia se asocia a los procesos cognitivos. Un total de 10 profesores, que corresponde al 30,3 \%, le dio relevancia a la interpretación de fuentes históricas y a la construcción del discurso histórico. La profesora P2 señala que «el treball amb fonts primàries i secundàries, analitzant i contrastant la informació que ofereixen i donant eines a l'alumne per construir el seu propi 
discurs». En la entrevista se hace más evidente su énfasis en la interpretación crítica de las fuentes orales al señalar "la importancia del contraste de las fuentes, de tipologías de fuentes diferentes, no solamente de fuentes diferentes, sino de tipologías diferentes es grande, porque es lo que te permite aproximarte a lo que es el análisis más certero, más ecuánime de lo que son los hechos, más completo, de los hechos que tú quieres estudiar o de las preguntas que tú te has hecho".

Cabe destacar que tres profesores justificaron las valoraciones en función de su propia experiencia personal sobre la metodología docente utilizada. P12 señaló que dio mayor valoración "en base a la frecuencia de uso» y P28 justifica en función de «l'experiència docent personal i d'altres companys».

\section{CONCLUSIONES}

La noción de EH ha sido utilizada en los planteamientos teóricos de las diferentes disciplinas de las ciencias sociales que buscan comprender la naturaleza de la construcción del conocimiento humano. Desde la filosofía y la teoría de la historia, la EH se entiende como la realidad vivida y experimentada por el sujeto cognoscente y se considera determinante en el momento de dar sentido al mundo social.

Desde la didáctica de las ciencias sociales la EH se ha mencionado como un elemento fundamental para el conocimiento histórico escolar. Se entiende que el saber histórico es una construcción humana que no está ajena a la realidad cultural, ideológica o histórica del estudiante (Pagès y Santisteban, 2011). El pensamiento histórico requiere del uso de habilidades y procedimientos que permitan interpretar el pasado, comprender el presente y proyectarse al futuro. Este proceso de significación no es de carácter universal ni objetivo, sino que es una producción intelectual autónoma que puede generar diversas interpretaciones y significados de una misma realidad histórica.

Esta investigación profundiza sobre la EH y su importancia en el aprendizaje histórico escolar desde las representaciones sociales de un grupo de profesores de ciencias sociales de Cataluña. A partir del análisis de los datos obtenidos de cuestionarios y entrevistas hemos podido levantar categorías analíticas para definir la $\mathrm{EH}$ desde una perspectiva epistemológica, reconocer su vinculación con el pensamiento histórico y distinguir las formas de desarrollarla en los procesos de enseñanza y aprendizaje.

Las reflexiones del profesorado nos han permitido entender esta noción desde la didáctica y elaborar una propuesta conceptual. La EH se relaciona con el conjunto de vivencias, conocimientos y acciones que experimenta el estudiante y que le permiten generar aprendizajes autónomos, singulares y significativos. La experiencia se 
convierte en histórica cuando trasciende el pasado y es utilizada por el alumnado como conocimiento para posicionarse en el presente y proyectarse al futuro. Además, es posible reconocer tres dimensiones conceptuales: la vivencial, la cognitiva y la aplicada. La dimensión vivencial se asocia a la realidad personal de los sujetos históricos. Incluye vivencias pasadas, representaciones sociales del alumnado e incorporación del componente emocional al aprendizaje. La dimensión cognitiva se asocia a la interpretación y la construcción de significados históricos y la disonancia cognitiva. La dimensión aplicada involucra metodologías activas y participativas, así como también la intervención social del alumnado.

Como plantea Seixas \& Peck (2004) «the job of history education is to work with these fragments of thinking and develop them so that students have a better basis upon which to make sense of their own live» (pp. 109-110). Por lo tanto, la EH debe enriquecer el pensamiento histórico del alumnado y tener utilidad para su formación desde una perspectiva intelectual, personal y social. Los resultados de la investigación nos han permitido reconocer vínculos entre las dimensiones de la $\mathrm{EH}$ con las competencias de pensamiento histórico. Esta relación es posible de visualizar en el siguiente esquema conceptual:

Figura 2. Experiencia histórica y pensamiento histórico

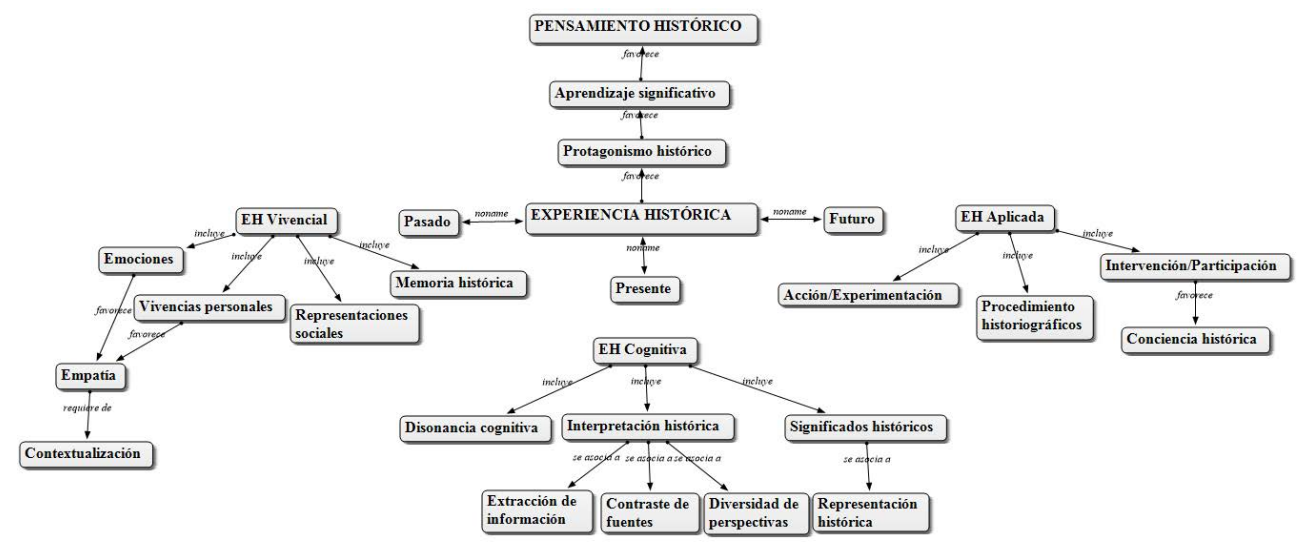

Fuente: Elaboración propia (Red semántica de Atlas-Ti).

Si la formación del pensamiento histórico se realiza considerando las tres dimensiones de la EH es posible favorecer el protagonismo histórico del alumnado. La EH propicia la interpretación y construcción de un aprendizaje autónomo basado en su realidad cercana, incluyendo sus vivencias, representaciones y emociones. Además, requiere de un aprendizaje activo a través de procedimientos historiográficos y orientados a la acción y la participación social, aspecto fundamental para la formación de la conciencia histórica. Por lo tanto, la EH actúa como un eje articulador 
de las competencias de pensamiento histórico y permite desarrollar aprendizajes significativos.

Se puede afirmar que la dimensión vivencial favorece el desarrollo de la empatía histórica porque el estudiante debe comprender las vivencias humanas en su contexto histórico, pero además puede producir emociones que impactan positivamente en el aprendizaje. La dimensión cognitiva requiere de la interpretación histórica a través de la extracción de información, la comparación de diversas perspectivas y el contraste de diversas fuentes históricas. En este proceso, el estudiante incluye aspectos personales, culturales e históricos en el momento de interpretar la información. También, la representación histórica debería elaborarse desde aspectos reales y cercanos, incluyendo reflexiones personales, perspectivas individuales e incluso sensaciones sobre lo aprendido. La dimensión aplicada se asocia a la conciencia histórica, competencia clave para entender el pasado, comprender su propia realidad y proponer alternativas para construir un mejor futuro. El aprendizaje debe permitir que el alumnado sea un agente de cambio, a través de la construcción de propuestas e instancias de participación, aspecto fundamental para la formación en competencias sociales y ciudadanas.

Finalmente, los resultados obtenidos permiten proponer tres estrategias para favorecer el desarrollo de la $\mathrm{EH}$ en los procesos de enseñanza y aprendizaje. Estas son: la utilización de recursos testimoniales, el desarrollo de actividades de interpretación histórica y el diseño de actividades con metodologías activas. Las fuentes primarias y los recursos testimoniales como la historia cercana o familiar y los proyectos de historia oral favorecen la $\mathrm{EH}$ por el grado de motivacióny compromiso del estudiante. A pesar de que la historia oral está limitada a la historia reciente-presente, se convierte en una estrategia potente porque le permite comprender la disciplina a partir de testimonios vivos del pasado. La interpretación crítica es un proceso cognitivo fundamental para favorecer el desarrollo de la EH del alumnado y le permite construir su propio discurso histórico. Por último, se deben realizar actividades de aprendizaje que requieran de una actitud activa, implicación personal y que tengan como protagonista central al propio estudiante.

El interés principal de esta investigación fue aportar otra perspectiva para entender el proceso de aprendizaje histórico. Entendemos la importancia de la adquisición de conocimientos y habilidades históricas, pero sostenemos que su utilidad es que se apropie de tal manera que se conviertan en EH para el alumnado. Para ello, se requiere de una innovación en las prácticas de enseñanza del profesorado, orientadas a un mayor protagonismo del alumnado y con un discurso histórico humanizado, donde las personas sean el centro de los estudios sociales. De esta manera, es posible que el alumnado pueda vivir la historia, hacer historia y entenderse como seres cargados de historicidad. 


\section{REFERENCIAS BIBLIOGRÁFICAS}

Anguera, C. (2012). El concepte de futur en l'ensenyament de les ciències socials. Estudis de cas a l' educación secundària. (Tesi doctoral). Universitat Autònoma de Barcelona, Barcelona. Recuperado el 2 diciembre de 2018, de <https:// www.tesisenred.net/handle/10803/117435>.

Ankersmit, F. (1993). La experiencia histórica. Historia y Grafía, 10, pp. 209-266. <http://studylib.es/doc/4905619/la-experiencia-hist\%C3\%B3rica-ankersmit-frank>.

Ankersmit, F. (2005). Sublime Historical Experience. California, Estados Unidos: Stanford University Press

Ankersmit, F. (2006a). The three levels of «Sinnbildung» in Historicail Weiting. En J. Rusën (ed.), Meaning \& Representation in History (pp. 108-122). New York/ Oxford: Berghahn Books.

Ankersmit, F. (2006b). Lenguage and Historical Experience. En J. Rusën (ed.), Meaning \& Representation in History (pp. 137-152). New York/Oxford: Berghahn Books.

Ankersmit, F. (2008). Experiencia Histórica Sublime. Santiago, Chile: Palinodia.

Belvedresi, R. (2011) Las dimensiones temporales de la experiencia histórica. VIII Jornadas de Investigación en Filosofía, La Plata: Espacios de diversión. <http:// www.memoria.fahce.unlp.edu.ar/trab_eventos/ev.1252/ev.1252.pdf>.

Cohen, M. y Manion, L. (1990). Métodos de Investigación Educativa. Madrid: La Muralla.

Dalongeville, A. (2003). Noción y práctica de la situación-problema en historia. En Enseñanza de las ciencias sociales: revista de investigación, 2, pp. 3-12. <http:// www.raco.cat/index.php/EnsenanzaCS/article/view/126144>.

Davison, M. (2012). Teaching historical empathy and the 1915 Gallipoli campaign. En M. Hartcourt, y M. Sheehan (eds.), History Matters: Teaching and Learning history in New Zealand schools in the 21st century (pp. 11-31). Wellington: NZCER Pres.

Domingo, A. (1993). Introducción: Historia y filosofía. En H. Gadamer, El problema de la conciencia histórica (pp. 9-38). Madrid: Tecnos. 
Flick, U. (2007). Introducción a la Investigación cualitativa. Madrid: Ediciones Morata.

Flick, U. (2015). El diseño de Investigación cualitativa. Madrid: Ediciones Morata.

Gadamer, H. (1977). Verdad y método. Fundamentos de una hermenéutica filosófica. Salamanca: Ediciones Sígueme.

Gadamer, H. (1993). El problema de la conciencia histórica. Madrid: Editorial TECNOS.

Gadamer. H (1995). El giro hermenéutico. Madrid: Ediciones Cátedra.

González, P. (2006). Conciencia Histórica y Enseñanza de la Historia: Una mirada desde los libros de texto. Enseñanza de Las Ciencias Sociales, 5, pp. 21-30. <https://www.raco.cat/index.php/EnsenanzaCS/article/view/126311>.

González-Monfort, N., Pagès, J., y, Santisteban, A. (2011). ¿Cómo evaluar pensamiento histórico? En P. Martínez, S. Molina y A. Santisteban (eds.), La evaluación en el proceso de enseñanza y aprendizaje de las ciencias sociales (vol. 1, pp. 221- 231). Murcia: AUPDCS. <http://www.didactica-cienciassociales.org/publicaciones_archivos/2011-murcia-La_evaluacion_I.pdf>.

Henríquez, R. (2009). Vivir en una historia lejana: Aprender a pensar históricamente en la heterogeneidad cultural. Íber Didáctica de las Ciencias Sociales, Geografía e Historia, 62, pp. 66-79

Ibáñez, A., Gillate, I. y Madariaga, J. M. (2015). Utilización de la historia oral para el aprendizaje de contenidos históricos en Educación Secundaria y su relación con la identidad local, la motivación y el autoconcepto social. Tempo e Argumento, 7(16), pp. 204-229. <http://revistas.udesc.br/index.php/tempo/article/ view/2175180307162015204>.

Lévesque, S. (2008). Thinking Historically. Educating Students for the Twenty-First Centur. Toronto: University of Toronto Press.

Llusà, J. (2015). Ensenyar història des de la contemporaneïtat estudi de cas sobre la construcció i aplicació del concepte contemporaneïtat a I'ESO. (Tesi doctoral). Universitat Autònoma de Barcelona, Barcelona. <https://www.tesisenred.net/ handle/10803/299792>. 
Mattozzi, I. (2011). Oltre il dovere della memoria: i compiti della scuola. En E. Perillo (a cura di), La colpa di essere nati. Marta Minerbi e Alessandro Ottolenghi: ebrei cittadini trevigiani (pp. 107-122). Treviso: Istresco.

Moscovici, S. (1979). El psicoanálisis, su imagen y su público. Buenos Aires: Huemul.

Muñoz, E. y Pagès, J. (2012). La relación pasado- presente en la enseñanza de la historia en la educación secundaria obligatoria catalana. Clio \& asociados, 16, pp. 11-38. <http://www.memoria.fahce.unlp.edu.ar/art_revistas/pr.5538/ pr.5538.pdf>.

Pagès, J. (2003). Ciudadanía y enseñanza de la historia. Reseñas de Enseñanza de la Historia, 1, pp. 11-42.

Pagès, J. (2009). El desarrollo del pensamiento histórico como requisito para la formación democrática de la ciudadanía. Reseñas de Enseñanza de la Historia, 7, pp. 69-91.

Pagès, J, y Santisteban, A. (2011). Enseñar y aprender ciencias sociales. En A. Santisteban y J, Pagès (coords.), Didáctica del conocimiento del medio social y cultural en la educación primaria. Ciencias sociales para aprender, pensar y actuar (pp. 23- 39). Madrid: Editorial Síntesis.

Pagès, J. y Santisteban, A. (2014). Una mirada del pasado al futuro en la didáctica de las ciencias sociales. En J. Pagès y A. Santisteban (eds.), Investigación e innovación en didáctica de las ciencias sociales (vol. 1, pp. 17-39). Barcelona: Servicio de Publicaciones de la UAB/ AUPDCS. <http://didactica-cienciassociales.org/wp-content/uploads/2013/11/XXVSIMPO1_v2.pdf>.

Plá, S. (2005). Aprender a pensar históricamente. La escritura de la historia en el bachillerato. México: Plaza y Valdés.

Plá, S. (2011). La enseñanza de la historia como objeto de investigación. Secuencia [online], 84, pp. 163-184. <http://www.scielo.org.mx/scielo.php?script=sci_ arttext\&pid=S0186-03482012000300007>.

Plá, S. y Pagès, J. (2014). Una mirada regional a la investigación en enseñanza de la historia en América Latina. En S. Plá y Pagès, J. (coord.), La investigación en enseñanza de la Historia en América Latina (pp. 13-38). México: Bonilla Artigas Editores. 
Plá, S. y Pérez, M. (2013). Pensar Históricamente como pasado reciente de México. Clío \& Asociados, 17, pp. 27-55. <http://www.memoria.fahce.unlp.edu.ar/art_ revistas/pr.6208/pr.6208.pdf>.

Ross, W. (2015). Teaching for change: Social education and critical knowledge of everyday life. In S. Totten (ed.), The importance of teaching social issues; Our pedagogical creeds (pp. 141-147). New York: Routledge.

Rüsen, J. (1992). El desarrollo de la competencia narrativa en el aprendizaje histórico. Una hipótesis ontogenética relativa a la conciencia moral. Propuesta Educativa, 7, pp. 27-36.

Rüsen, J. (2001). What is Historical Consciousness? A Theoretical Approach to Empirical Evidence. Paper presented at the Canadian Historical Consciousness in an International Context: Theoretical frameworks, Centre for the Study of Historical Consciousness. Vancouver: University of British Columbia.

Rüsen, J. (2007). Memory, history and the quest for the future. En L. Cajani y A. Ross (eds.), History Teaching, Identities and Citizenship: European Issues in Children's Identity and Citizenship (7) (pp. 13-34). London: Trentham Books (Staffordshire).

Sabariego, M. (2004). El proceso de la investigación (parte 2). En R. Bisquerra (coord.), Metodología de la investigación educativa (pp. 127-163). Madrid, España: Editorial La muralla.

Saiz, J. y Fuster, C. (2014). Memorizar historia sin aprender pensamiento histórico. Las PAU de Historia de España. Investigación en la escuela, 84, pp. 47-57. <https://idus.us.es/xmlui/handle/11441/59755>.

Santisteban, A. (2005). Les representacions i l'ensenyament del temps històric. Estudis de cas en formació inicial de mestres de primària en Didàctica de les Ciències Socials. (Tesi doctoral). Universitat Autònoma de Barcelona, Barcelona. <https://www.tesisenred.net/handle/10803/4666>.

Santisteban, A. (2010). La formación en competencias de pensamiento histórico. En Clío \& Asociados. La historia Enseñada, 14, pp. 34-55. <https://www.clio.fahce. unlp.edu.ar/article/view/clion14a03>.

Santisteban, A., González-Monfort, N. y Pagès, J. (2010). Una investigación sobre la formación del pensamiento histórico. En R. M. Ávila, P. Rivero y P. L. Domínguez (coords.), Metodología de investigación en Didáctica de las Ciencias Sociales 
(pp. 115-128). Zaragoza: Fernando el Católico/AUPDCS. <https://ifc.dpz.es/ publicaciones/ebooks/id/2971>.

Shulman, L. S. (1986). Those who understand: Knowledge growth in teaching. Educational Researcher, 15(2), pp. 4-14. doi: <https://doi. org/10.3102/0013189X015002004>.

Seixas, P. \& Peck, C. (2004). Teaching historical thinking. En A. Sears y I. Wright (eds.), Challenges and Prospects for Canadian Social Studies (pp. 109-117). Vancouver: Pacific Educational Press.

Simons, H. (2011). El estudio de caso: teoría y práctica. Madrid: Ediciones Morata.

Stearns, P. (2004). Thinking History. Washington D. C: American Historical Association.

Soria, G. (2014). El pensamiento histórico en la educación primaria: estudio de casos a partir de las narraciones históricas. (Tesis doctoral). <http://www.tdx.cat/ bitstream/handle/10803/285095/gmsl1de1. pdf; sequence=1>.

Van der Maren, J. M. (1995). Méthodes des recherche pour l'éducation. Bruselas: De Boeck-Wesmael.

Van Maner, M. (2003). Investigación educativa y experiencia vivida. Barcelona: Colección Idea Universitaria

Wineburg, S. (2001). Historical Thinking and other Unnatural Acts: Charting the Future of teaching the past. Philadelphia: Temple University Press.

Yuste, M. (2017). L'empatia i l'ensenyament-aprenentatge de les Ciències Socials a l'Educació Primària a Catalunya. Un estudi de cas. (Tesi doctoral). Universitat Autònoma de Barcelona, Barcelona. <https://www.tesisenred.net/ handle/10803/402238>. 